\title{
Deepening Mathematics Learning by Making Variation Available in Teaching
}

\author{
Su Liang \\ University of Texas at San Antonio
}

Active engagement does not necessarily produce meaningful mathematical learning. It is not uncommon that in mathematics classrooms students seemed to be engaged in-class activities, be happy with what has been done, and everybody enjoyed the lessons, but the assessment revealed that students only learned some factual knowledge on the surface failing to apply the learned knowledge to solve related problems. What is the missing part of the puzzle? Students learn through experiencing the available content. Active engagement does not produce meaningful mathematical learning if some essence of content is missed. If we want our students to learn structured mathematics and be able to apply what have learned to a new situation or context, we must make this kind of learning content available in a mathematics classroom. transfer of learning will never happen without intentionally designed content. "What" needs to be learned should be always the starting and ending point of our teaching/learning design. This paper discusses the existing issue and proposes some pedagogical strategies to promote deep learning.

Keyword: variation, multi-dimensional tasks, meaningful connections, deep learning, the object of learning, prior knowledge

\section{INTRODUCTION}

It is not uncommon that in mathematics classrooms students seemed to be engaged in class activities, be happy with what have been done, and everybody enjoyed the lessons, but the assessment revealed that students only learned some factual knowledge on the surface failing to apply the learned knowledge to solve related problems. What is the missing part in the puzzle? If we closely look into the class activities, we can see that the content of the class activities is too simple to facilitate deep learning. Many existing instructional theories provide guidance for teachers to use effective teaching formats such as studentcentered teaching, inquiry-based learning, use of technology, group work, collaborative learning. However, teaching formats and classroom management are not the content - the object of learning. We learn through experiencing the available content (Marton and Booth,1997; Marton 2015), and "we cannot think without something being thought about...... we cannot learn without something being learned" (Lo, 2012, p.15). Based on some meta-analyses of the studies of curriculum reform, Pong and Morris (2002) argued that how teachers made the object of learning available to their students, had a critical effect on student learning outcomes. Knowing how to choose appropriate content is crucial for teachers (Liang, 2013). This paper introduces a strategy of making the object of learning available for students to explore from various perspectives instead of simply from one way of thinking. A vision of variation widens and deepens student learning dimension. It is necessary for teachers to design class activities that apply a mathematical 
concept/idea from multiple angles of thinking if we want our students to avoid the habit of linear thinking and be able to solve mathematical problems embedded in different situations.

\section{Making Variation Available in Teaching Is Necessary for Deep Understanding}

Human beings learn from difference. Variation is a necessary condition of learning (Marton \& Booth, 1997). A learner must be able to discern the critical aspects of the object of learning by simultaneously experiencing potential alternatives in order to discern new aspects of the object (Marton \& Pang, 2006). Higher level of Learning happens when one, who has learned to do something in one situation, are able to do something different in other situations by perceiving differences between situations (Bloom, 1956; Marton \& Pang, 2006). To provide opportunities for students to access a better learning outcome, as a teacher we must craft tasks that facilitate higher levels of learning. An effective teacher is not only teaching certain subject matter, but also assisting students to discern how a certain subject matter is related to the entire subject structure with respect to prior learning and future learning (Lo, 2012). Deep learning takes places only when a student knows both the meaning and the structure of the object of learning. The evidence of transfer of learning is being able to apply learned knowledge and skills to different situations (Noe, 2012; Mariano, 2014). Knowledge cannot be transferred without having students experience an appropriate pattern of variation; metacognition requires discernment of critical features of a subject matter. In a study conducted by Eddyie Cheng (2016), students showed significant improvement in discerning the object of learning after doing the tasks with the patterns of variation. Variation is "a necessary condition for learners to be able discern new aspects of an object of learning" (Kullberg, Kempe, \& Marton, 2017).

What being learned and how to learn the "what" are very important for a teacher to ponder carefully. We design "learning experiences for students to make it possible for them to appropriate the object of learning" through "studying the object of learning carefully, finding our students' learning difficulties, identifying the object's critical features, and designing appropriate patterns of variation that help students to discern the critical features and their relationships" (Lo, 2012, p. 195). Variation of tasks deepens learning by engaging students in multiple-perspective thinking. To make variation available for students to experience, we may concentrate on the five considerations when designing lesson tasks:

1. Consider what certain prior knowledge needs to be used and how the prior knowledge can help build new understanding.

2. Consider what new knowledge/object of learning needs to be developed and how to address some critical issues.

3. Consider what variation needs to be presented for students to discern the critical aspects of the new knowledge.

4. Consider what questions can engage students in comparing and contrasting the application of the involved knowledge at different situations.

5. Consider what future knowledge is related to the new knowledge and how they are related.

All of the five considerations focus on how to make the object of learning available to students from different perspectives. Making a content available from various perspectives is necessary in order to have students experience what they are projected to learn and to understand the critical aspects of the object of learning through engaging. Unlike fact-checking tasks, multiple-perspective tasks go deep beyond factual knowledge and help students with making sense of meaning. A teacher should always identify the critical aspects and make them available for students. How can the five recommended considerations be applied to designing tasks that facilitate multiple-perspective thinking? In the next section, a set of tasks will be shared to demonstrate the application and articulately show the answer for the question.

\section{Applying the Five Considerations to Design Tasks of Facilitating Multiple-Perspective Thinking}

The set of lesson tasks is developed to help students learn the commonly used theorem - Pythagorean Theorem (PT) and its application from multiple perspectives. The five considerations was incorporated into designing the set of tasks as described below. 


\section{Consider What Prior Knowledge Needs to Be Used and How the Prior Knowledge Can Help Build New Understanding}

To learn PT, one should have known the definition of a right triangle and the difference between a right triangle and other triangles, because PT is only applicable to right triangles. The relationship entailed by PT exists in right triangles and only right triangles make PT valid; in another word, right triangles are the necessary condition for PT. Very commonly students inappropriately apply PT to non-right triangles. Therefore, the necessary condition of PT must be explicitly emphasized throughout the learning/teaching process. A starting task can be added here: Look at the picture below, explain the relationship of the three sides in the right triangle $A B C$. Exploration of this task would help students understand how PT can be generated. Students are expected to see the sum of the area of the square with the side length $A C$ and the area of the square with the side $B C$ is the same as the area of the square with the side length $A B$. The equivalent mathematical expression is $A C^{2}+B C^{2}=A B^{2}$. This picture given below articulates why and how the PT can be generated.

FIGURE 1

\section{ONE WAY OF GENERATING THE PD}

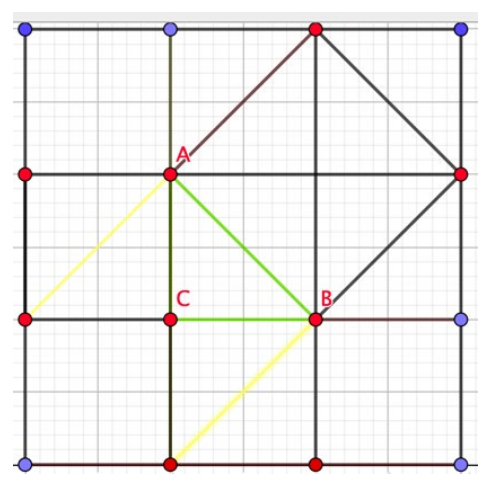

\section{Consider What New Knowledge/Object of Learning Needs to Be Developed and How to Address Some Critical Issues}

PT is the new knowledge - the intended object of learning that we want our students to develop understanding. The often-observed issue is that students don't make meaningful connection between the mathematical expression of $a^{2}+b^{2}=c^{2}$ and the respectively corresponding side of $a, b, c$ in a right triangle. For example, in my preservice elementary content courses, often times when being asked about PT, some preservice teachers would immediately reply " $a^{2}+b^{2}=c^{2}$ ", but they were not able to answer the follow-up questions: what do $a, b, c$ represent? In what situation is " $a^{2}+b^{2}=c^{2}$ " true? This is a typical example of memorizing without understanding. Memorizing something without understanding creates hurdles for students to learn new knowledge. When teaching PT, we should explicitly emphasize that PT indeed describes the property of right triangles. Some examples of acute triangles and obtuse triangles may be presented for comparison purpose. Some teachers may think that consistently using " $a^{2}+$ $b^{2}=c^{2}$ " helps students memorize PT. However, the invariance has a negative impact on learning. On the one hand, this make-things-easy-practice stimulates linear thinking and rote learning. The misunderstanding for PT can persist and hinder future learning. When teaching PT, instead of having students rote memorizing " $a^{2}+b^{2}=c^{2}$ ", we should emphasize that what $a, b, c$ represented here really depends on how we define them in a right triangle. The hypotenuse can be also represented by either $a$ or $b$, the legs of a triangle can be represented by either the pair of $b$ and $c$ or the pair of $a$ and $c$. Corresponding to the change of representing letters, the Pythagorean theorem can be expressed as $b^{2}+$ $c^{2}=a^{2}$, where $b, c$ are the legs of the triangle and $a$ is the hypotenuse of the triangle; or $a^{2}+c^{2}=b^{2}$, where $a, c$ are the legs of the triangle and $b$ is the hypotenuse of the triangle. Furthermore, the legs and the hypotenuse of a right triangle can be represented by any letters, so the PT can be written as $d^{2}+e^{2}=f^{2}$, 
where $d, e$ are the legs of the triangle and $f$ is the hypotenuse of the triangle. It is also necessary here to make sure students are able to use words precisely describing the PT and connect the word description to the corresponding mathematical expression.

\section{Consider What Variation Needs to Be Presented for Students to Discern the Critical Aspects of the New Knowledge}

After explicitly demonstrating the underlying relationship in PT, we should let students experience applying PT at different situations by providing a set of various problems that help discern the critical aspects of PT:

1. A warm-up question: If we are given two sides of a triangle, can we use PT to find the third side of the triangle? Why?

2. A straightforward question: given the two legs of a right triangle, find the hypotenuse. Provide mathematical reasoning to validate what you did.

3. A non-straightforward question: given one leg and the hypotenuse of a right triangle, find another leg. Provide mathematical reasoning to validate what you did.

4. A backward thinking question: given three sides of a triangle, determine if the triangle is a right triangle. Provide mathematical reasoning to validate what you did.

The first question intends to have students make necessary connection between PT and a right triangle. Thinking about this question enhances one of the critical aspects of PT - PT applies only if a triangle is a right triangle. Noticing that the other three questions can be solved by applying PT at different situations. In my preservice teacher classes, although the students had learned PT at high school, I still observed the common mistakes made in question 2 and question 3. For question 2, there were always some students taking the square of the given leg and the square of the hypotenuse, adding the squares, and then taking the square root to find another leg. For question 3, some students failed to connect this question to PT; some students did not realize that the candidate of hypotenuse should be the longest side and reached a wrong conclusion. Correcting these mistakes provides opportunities for students to experience applying PT from different perspectives.

\section{Consider What Questions Can Engage Students in Comparing and Contrasting the Application of the Involved Knowledge at Different Situations}

Meaning-making needs reflective thinking. Students should be provided opportunities to reflect on what have done. Following the three questions, a metacognitive question can be given:

5. Comparing the three problems above, what variations do you observe? How are the questions different?

This question allows students to reflect on what they have done and recognize the variations of applying PT at different situations. Reflective thinking makes it possible for transfer of learning from knowing PT to using PT as a problem-solving tool at a new situation.

\section{Consider What Future Knowledge Is Related to the New Knowledge and How They Are Related}

Each piece of knowledge to a system of knowledge is like a building block to a house. PT is an important building block fundamental to a lot of mathematics knowledge. To give a few examples, knowing PT prepares students to learn how the distance formula is developed and the trigonometric identity $\sin ^{2} \theta+$ $\cos ^{2} \theta=1$ in a unit circle. Knowing the distance formula helps build understanding of the equations of a circle, a parabola, an ellipse, and a hyperbola. Since PD can be directly used to deduct the distance formula and the trigonometric identity, we may extend student learning from understanding PD to applying PD to prove mathematical formula and identity. Two more questions can be added:

6. Given two points $P 1(x 1, y 1)$ and $P 2(x 2, y 2)$, can you use PT develop a mathematical expression for the distance between $P 1$ and $P 2$ in terms of $x 1, x 2, y 1, y 2$ ?

7. Use PT to prove the trigonometric identity $\sin ^{2} \theta+\cos ^{2} \theta=1$. 


\section{FIGURE 2}

\section{USING PT TO PROVE THE DISTANCE FORMULA AND THE TRIGONOMETRIC IDENTITY}

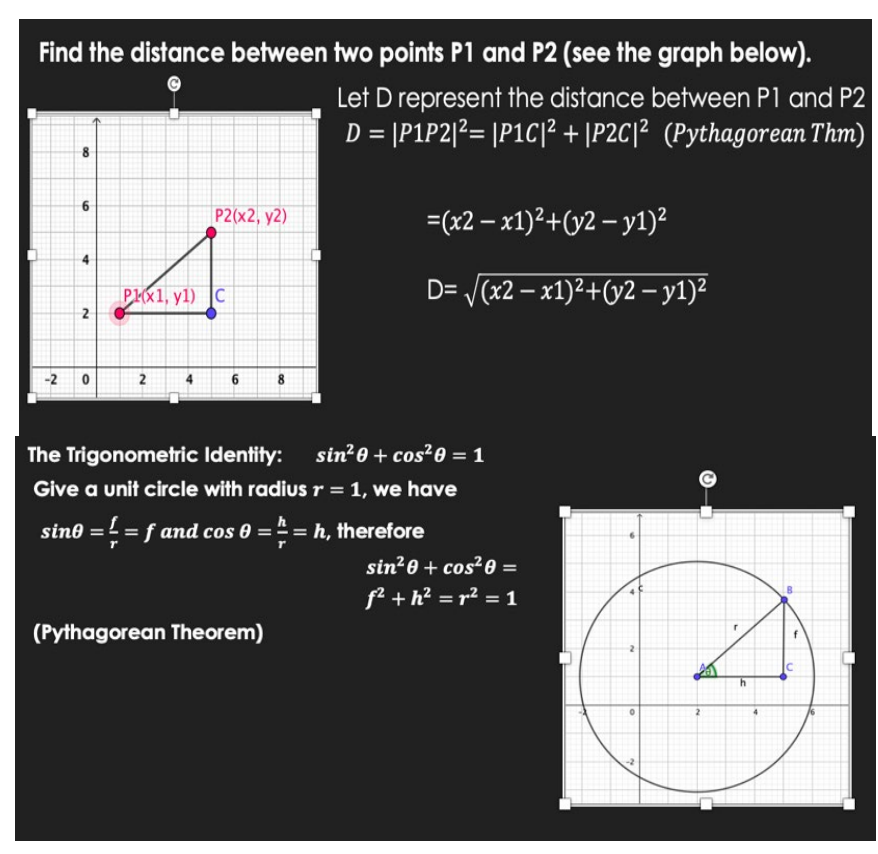

A comparison table is crated to summarize the set of tasks as follows.

\section{TABLE 1}

\section{A SUMMARY OF THE FIVE CONSIDERATIONS IN TASK DESIGN}

\begin{tabular}{|c|c|}
\hline $\begin{array}{l}\text { The Five Considerations When } \\
\text { Designing Variation }\end{array}$ & The Selected Task(s) Corresponding to the Specific Principle \\
\hline $\begin{array}{l}\text { 1. Consider the prior } \\
\text { knowledge (PK) and the } \\
\text { connection between the PK } \\
\text { and the new knowledge. }\end{array}$ & $\begin{array}{l}\text { What is a right triangle? } \\
\text { - How is a right triangle different from a general triangle? } \\
\text { Explain the relationship of the three sides in the right triangle } \\
A B C \text { based on the picture given: }\end{array}$ \\
\hline $\begin{array}{l}\text { 2. Consider the object of } \\
\text { learning and the critical } \\
\text { issues involved. }\end{array}$ & $\begin{array}{l}\text { Can } c \text { represent one leg of a right triangle? } \\
\text { - Can the hypotenuse of a right triangle be represented by } \\
\text { a or b or other letters? } \\
\text { - Use words to describe PT precisely and base on your } \\
\text { description to write a corresponding mathematical expression. }\end{array}$ \\
\hline $\begin{array}{l}\text { 3. Consider the examples of } \\
\text { variation that help discern } \\
\text { the critical aspects of the } \\
\text { new knowledge. }\end{array}$ & $\begin{array}{l}\text { If we are given two sides of a triangle, can we use PT to find } \\
\text { the third side of the triangle? Why? } \\
\text { A right triangle has two legs of } 9 \text { inches and } 14 \text { inches, can } \\
\text { you find the hypotenuse? Provide mathematical reasoning to } \\
\text { validate what you did. } \\
\text { - A computer monitor has the diagonal of } 73 \mathrm{~cm} \text { and the width }\end{array}$ \\
\hline
\end{tabular}




\begin{tabular}{|c|c|}
\hline & $\begin{array}{l}\text { of } 55 \mathrm{~cm} \text {. What is the width of the computer? Provide } \\
\text { mathematical reasoning to validate what you did. } \\
\text { A triangle has three sides measured with } 2.5 \text { inches, } 2 \text { inch, } \\
\text { and } 1.5 \text { inches. Is this triangle a right triangle? Provide } \\
\text { mathematical reasoning to validate what you did. }\end{array}$ \\
\hline $\begin{array}{l}\text { 4. Consider the questions that } \\
\text { engage comparing the } \\
\text { application at different } \\
\text { situations. }\end{array}$ & $\begin{array}{l}\text { Comparing the three problems above, what variations do you } \\
\text { observe? } \\
\text { - How are the questions different? }\end{array}$ \\
\hline $\begin{array}{l}\text { 5. Consider the related future } \\
\text { knowledge }\end{array}$ & $\begin{array}{l}\text { Given two points } P 1(x 1, y 1) \text { and } P 2(x 2, y 2) \text {, can you use PT } \\
\text { develop a mathematical expression for the distance between } \\
P 1 \text { and } P 2 \text { in terms of } x 1, x 2, y 1, y 2 \text { ? } \\
\text { - Use PT to prove the trigonometric identity } \sin ^{2} \theta+\cos ^{2} \theta=1 \text {. }\end{array}$ \\
\hline
\end{tabular}

Variation of tasks not only emphasizes teaching the object of learning from different perspectives but also promotes different ways of thinking, because meaning-making primarily originate from difference and sameness plays a secondary role (Lo, 2012). Being able to use multiple representations flexibly and accurately is essential for comprehensive understanding and successful mathematical problem solving (Dreher \& Kuntze, 2015). Teaching can help a better learning if a teacher encourages different ways of mathematical thinking and different methods to solve a problem. However, we need to make this kind of teaching available for students to experience.

\section{Engaging Students in Solving One Problem Using Different Methods}

Mathematics is not a pile of unorganized knowledge isolated to each other. Learning mathematics is about understanding a systematically structured relations between concepts/ideas and applying the understanding to solve related problems at different situations. Failing to experience all the critical aspects of the object of learning creates blinded spots for students to reach a fully understanding of certain concepts/ideas. As a result further advanced learning will become very hard to reach and fail eventually. It is crucial for a teacher to make connected mathematics available for students to experience in a classroom in order to help students understand thoroughly and apply appropriately to solve related problems at different situations. When selecting a task, we should choose the ones that can be solved by different methods. Students' learning horizon is extended through 'seeing' alternative ways of mathematical thinking. According to Marton and Tsui (2004), powerful ways of seeing generate powerful ways of acting. To increase students' capability of problem solving and adapting new situations, teachers should create opportunities for students to develop powerful ways of seeing (Lo, 2012). Designing teaching that facilitates different ways of mathematical thinking is very important to power students' seeing and learning. An example is given here to shed a light on teaching connected mathematics by solving a problem using different methods. The set of problems was used in my preservice secondary mathematics teachers' content course.

Farmer John has 144 linear feet of fencing and wants to create a rectangular pen for his pigs.

1. What arrangement of the fencing will give the pigs the largest area in which to roam?

2. Reflecting on the process of solving the problem, what connected mathematical ideas do you see? Do you see how arithmetic, algebra, geometry, and calculus are related in the problem?

We can expect to have three different methods to solve the first question of this problem.

\section{Arithmetic Method}

List possible cases and conclude the result based on the pattern observed. Since a rectangle has two pairs of equal sides, so we only need to consider the pairs of numbers adding up to 72 inches (144 ft/2). 
TABLE 2

THE DIFFERENT COMBINATIONS OF LENGTH AND WIDTH FOR THE RECTANGULAR PEN

\begin{tabular}{|l|l|l|l|}
\hline Length & Width & Perimeter & Area \\
\hline $\mathbf{7 2}$ & 2 & 144 & 140 \\
\hline $\mathbf{6 8}$ & 4 & 144 & 272 \\
\hline $\mathbf{6 6}$ & 6 & 144 & 396 \\
\hline$\ldots \ldots$ & $\ldots \ldots$ & $\ldots \ldots$ & $\ldots \ldots$ \\
\hline $\mathbf{3 8}$ & 34 & 144 & 1292 \\
\hline $\mathbf{3 6}$ & 36 & 144 & 1296 \\
\hline $\mathbf{3 4}$ & 38 & 144 & 1292 \\
\hline $\mathbf{6}$ & 66 & 144 & 396 \\
\hline $\mathbf{4}$ & 68 & 144 & 272 \\
\hline $\mathbf{2}$ & 72 & 144 & 140 \\
\hline
\end{tabular}

\section{Algebraic Method}

Let $x$ be the length of the pen and $y$ be the width of the pen. We have

$$
2 x+2 y=144 ; y=72-x
$$

Then the area can be represented by the function:

$$
A_{(x)}=x(72-x)=72 x-x^{2}=-x^{2}+72 x
$$

By completed square, we have: $A_{(x)}=-(x-36)^{2}+1296$, which says that the graph of the area function is concave-down (see the graph below) and have a maximum area of $1296 \mathrm{inch}^{2}$ at $x=36 \mathrm{inch}$. When $x=36, y=72-36=36$. Therefore the pen has the largest area when the fence is arranged as a square with 36 -inch side.

FIGURE 3

THE GRAPH OF FUNCTION A(x) $=-x^{2}+72 x$

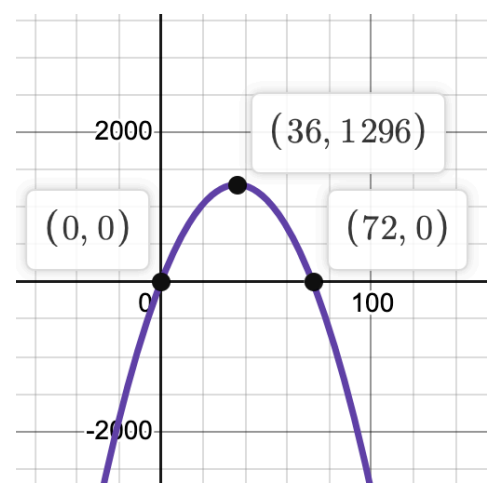




\section{Calculus Method}

This is an optimization problem in Calculus. Let $x$ be the length of the pen and $y$ be the width of the pen. We have

$$
2 x+2 y=144 ; y=72-x
$$

Then the area can be represented by the function:

$$
A_{(x)}=x(72-x)=72 x-x^{2}=-x^{2}+72 x
$$

Furthermore,

$$
A_{(x)}{ }^{\prime}=-2 x+72
$$

Set up $-2 x+72=0$, we can find the critical point $x=36$, and at the critical point, $A_{(x)}{ }^{\prime}$ changes signs from positive to negative. Using the first derivative test, we can conclude that when $x=36 \mathrm{inch}$, we have the maximum area which is 36 inch $\times 36$ inch $=1296$ inch $^{2}$.

The second question of the problem intends to motivate reflective learning and push students to see the connection between mathematical ideas across topics. The same problem can be extending as follows:

- Farmer John has 144 linear feet of fencing and wants to create a pen for his pigs. He wants the shape of the pen to be either rectangular or circular. What arrangement of the fencing will give the pigs the largest area in which to roam?

This extended problem adds one more choice for arranging the fence. If the shape is circular, we have $2 \pi r=144$, and solve the equation for $r$, we get $r=\frac{72}{\pi}$, the area of the circular pen $=\pi r^{2}=\pi \cdot\left(\frac{72}{\pi}\right)^{2} \approx$ $1650.96 \mathrm{ft}^{2}$ which is larger than the maximum rectangular area $1296 \mathrm{ft}^{2}$.

The different methods of solving the same problem help students envision the connected mathematics and recognize how mathematical ideas and topics can be entwined together. Most of the preservice secondary teachers had never been experienced this kind of connected mathematics before seeing this problem. In their reflection, they appreciated that different ways of solving the problem made them see how mathematical knowledge is related horizontally (among topics) and vertically (cross grade levels). This problem allows an extended space for students to explore from different standing points and therefore produce non-linear thinking at more than one dimension Multi-dimensional tasks make a more complete picture of mathematical features available for students to see and build deep and systematics understanding of mathematics.

\section{CONCLUSION}

Most teaching strategies focus on teaching format or classroom management, which emphasizes "how to engage students" in order to ultimately reach effective learning outcomes. Without a doubt, actively engaging students is very important for a better learning. However, students learn from what we make available to engage them, they cannot learn what they never see and experience. If teaching format is important for an effective learning, then what-made-available - the object of learning is a necessary condition for capacity of learning. Although making multi-dimensional tasks available does not guarantee deep learning for every student, unavailability of multi-dimensional tasks will make a better learning outcome impossible for all students. No matter what teaching format enacted, you name it, studentcentered, inquired-based, project-based, or collaborative learning, transfer of learning will never happen without intentionally designed content - the direct object of learning. "What" needs to be learned should be always the starting and ending point of our teaching/learning design. Making the critical aspects of learning object available should never be overlooked. Active engagement does not produce meaningful mathematical learning if some essence of content is missed. If we want our students to learn the structured 
mathematics and be able to apply what have learned to a new situation or context, we must make this kind of learning content available in mathematics classroom. Variation helps design multi-dimensional tasks and can be applied to serve as a promising effective strategy for mathematics educators to develop rich tasks for deep learning.

\section{REFERENCES}

Bloom, B.S. (1956). Taxonomy of Educational Objectives (Vol. 1). Cognitive Domain. New York: McKay.

Cheng, E.W.L. (2016). Learning through the Variation Theory: A Case Study. International Journal of Teaching and Learning in Higher Education, 28(2), 283-292. ISSN 1812-9129

Dreher, A., \& Kuntze, S. (2015). Teachers' professional knowledge and noticing: The case of multiple representations in the mathematics classroom. Educational Studies in Mathematics, 88, 89-114. doi: $10.1007 / \mathrm{s} 10649-014-9577-8$

Liang, S. (2013). An examination of the preparation and practice of grades 7-12 mathematics teachers from the Shandong Province in China. Journal of Mathematics Teacher Education, 16(2), 149160. ISSN 1386-4416

Lo, M.L. (2012). Variation Theory and the Improvement of Teaching and Learning. Goteborg: Acta Universitatis Gothoburgensis. ISBN 978-91-7346-725-4

Mariano, G. (2014). Breaking it down: Knowledge transfer in a multimedia learning environment. International Journal of Teaching and Learning in Higher Education, 26(1), 1-11.

Marton, F. (2015). Necessary conditions of learning. New York: Routledge.

Marton, F., \& Booth, S. (1997). Learning and awareness. Mahwah N.J.: Lawrence Erlbaum.

Marton, F., \& Pang, M.F. (2006). On Some Necessary Conditions of Learning. The Journal of the Learning Sciences, 15(2), 193-220.

Marton, F., \& Tsui, A.B.M. (2004). Classroom discourse and the space of learning. Mahwah, NJ: Lawrence Erlbaum Associates.

Noe, R.A. (2012). Employee training and development (6th ed.). New York, NY: McGraw-Hill.

Pong, W.Y., \& Morris, P. (2002). Accounting for differences in achievement. In F. Marton \& P. Morris, What matters? Discovering critical conditions of classroom learning. Goteborg: Acta Universitatis Gothoburgensis. 